\title{
A POÉTICA DA MENTIRA: CRISE DA METAFÍSICA E PERCEPÇÃO DO SAGRADO EM UMA LEITURA DE CENTÚRIA, DE GIORGIO MANGANELLI
}

RESUMO:

Numa leitura de Centúria, de Giorgio Manganelli, que explora a derrocada da legitimação metafísica das noções de ser e de real, analisa-se a dissolução da noção de sagrado, enquanto princípio suficiente de legitimação do conhecimento da verdade $e$ de proteção contra o caos.

PALAVRAS-CHAVE: sagrado, metafísica, ficção, realidade.

Um escritor inconfundivel, um inventor inexaurível no jogo da linguagem e das idéias: é com essas palavras que Italo Calvino apresenta a tradução francesa de Centúria - cem pequenos romances-rio, de Giorgio Manganelli. Um autor essencial para quem deseja conhecer a literatura italiana dos últimos decênios, continua Calvino, chegando mesmo a afirmar entusiasticamente que, pela interação criativa e inovadora com a tradição literária de seu país, Manganelli é "o mais italiano dos escritores" (1998: 9).

Calvino não é o único a sustentar tal afirmação. Freqüentemente, as obras de Manganelli são associadas aos clássicos da literatura italiana. Lombardi (1993), por exemplo, identifica um diálogo entre a narrativa Hilarotragoedia e a Divina Comédia, de Dante Alighieri; e Barni (1995), baseando-se em Lorenzo Mondo, considera Centúria uma "reescritura" irreverente, irônica e, por vezes, sarcástica do Novellino - conjunto de textos que representa o surgimento da novelística toscana (ca. 1280-1300).

* Mestre em Letras: Estudos Literários (Área de concentração: Teoria da Literatura), 2001. 


\section{EM TESE}

Belo Horizonte, v. 6, p. I-253, ago. 2003

Contudo, ao mesmo tempo em que Manganelli é reiteradamente apresentado como um autor arraigado nessa tradição literária, é também "o mais isolado na literatura italiana" porque "demole sem piedade todas as intenções virtuosas e didascálicas" que dominaram as letras, na Itália dos séculos XIX e XX, pondo em questão "toda pretensão de contar em qualquer modo na história da sociedade", como observa Calvino (1998: 10).

Tomando como referência significativa o seu texto teórico La letteratura come menzogna [A literatura como mentira] (1985), pode-se afirmar que Manganelli se inscreve numa tradição filosófica que põe em xeque a pretensão de fazer da razão o único princípio explicativo da realidade. Manganelli evidencia, numa espécie de "poética da mentira", a fragilidade dos sistemas "fundacionistas", os quais negam a origem fictícia e criativa de seus próprios postulados. Segundo Pimenta, tais sistemas pretendem "desvendar o ser capturando a verdade", mas são carentes de "certezas e pontos de ancoragem invulneráveis à ação da dúvida" (1999: 101), que 1hes garantam atingir essa meta. Manganelli parece propor uma epistemologia em que, ao contrário da neutralidade e objetividade que os projetos fundacionistas buscavam ostentar, o saber aparece como um discurso e, como tal, submetido a regras e valores. Em outras palavras, não há uma verdade absoluta. Esta passa a ser descrita como uma ilusão ou como um artifício intelectual, uma construção.

Em Centúria, Giorgio Manganelli procura explorar a crise gerada por tal reformulação epistemológica. Se não há um princípio fundante para a verdade, o que pode dar ao que comumente se chama realidade um estatuto superior ao que se atribui à ficção, à fantasia, à alucinação, ao sonho, à embriaguez? 0 real se amplia e passa a integrar também o ficcional, o ideal, o ilusório, o fantástico, o onírico e, ainda, o inexistente, o próprio nada. Não se trata de uma mera inversão entre o convencionalmente denominado real e outras formas discursivas que não o são, mas sim de uma tessitura em que o supostamente real se combina e se confunde com 0 que não tem esse estatuto.

A ironia - talvez uma das principais características do texto manganelliano - é marcada pela descrença na capacidade de significação das palavras: 
Si suppone che una certa parola, scelta dall'autore, come per comodità diciamo, abbia il senso che quel tal signore abbia voluto. [...] Direi che le parole hanno tutti $i$ sensi meno quell'unico che eventualmente qualcuno abbia cercato di "mettervi". (Manganel1i, 1982: 31)

[Supõe-se que uma certa palavra, escolhida pelo autor, digamos, por comodidade, tenha 0 sentido que deseja aquele tal senhor. [...] Diria que as palavras têm todos os sentidos menos aquele único que eventualmente alguém tenha procurado "colocar nela".] (Tradução minha.)

Não é apenas a distância entre a palavra e o que ela designa que está em questão, mas também o fato de que dificilmente se distingue o real do imaginário ou do irreal. Essa ambigüidade foi apontada por Octavio Paz como característica da ironia moderna, que procede afirmando a ausência de identidade, a "realidade problemática, heróis problemáticos e linguagem problemática" (1991: 108).

Essa crise de significação que matiza também a ironia manganelliana se origina de uma crise da metafísica, ou seja, da impossibilidade de fundamentação da verdade, da inexistência de um princípio que a institua e a legitime. Um discurso só é válido dentro de determinadas regras convencionalmente construídas. Noções como ser, mundo, real ou realidade - ao invés de serem consideradas como paradigmas ou critérios pelos quais se possa sair das "trevas do erro" rumo a uma "verdade fulgente" - são percebidas como um artifício intelectual igualmente verificável e falseável.

Talvez uma importante chave de interpretação para o Centúria seja a metáfora dos "romances-rio" do subtítulo do livro. Essa imagem, que reporta ao célebre aforismo de Heráclito - "Tu não podes descer duas vezes no mesmo rio, porque novas águas correm sempre sobre ti" (D12) - parece enfatizar o caráter mutável, sempre fluente, continuamente novo da "realidade", em Manganelli, sempre problemática.

A unidade ou a identidade subjacentes à "multiplicidade aparente" é, tanto para Manganelli como para Heráclito, uma "unidade de tensões opostas" (Pessanha 1996: 24). Deve-se ressalvar que o termo "unidade" não é uma solução apaziguadora das tensões, como se, na unidade, as oposições se neutralizassem. Ao invés disso, é a importância atribuída à contradição, fundamental na noção de ser de Manganelli, que the permite fazer conviverem indistintamente ser e nada, fantástico e real, sanidade e loucura. Em Centúria, essas oposições não implicam a supressão de um de seus termos. Estes, mesmo sendo contraditórios, não se excluem; interpenetram-se. 


\section{EM TESE}

Belo Horizonte, v. 6, p. I-253, ago. 2003

À questão filosófica "por que existe o ser e não o nada?", Manganelli responderia que ambos são uma só e mesma coisa. 0 ser não tem maior realidade que o não ser; o ser é tão pouco como o não-ser. Um pode ser reconhecido no outro. 0 nada é algo que resvala o real, o existente tangencia o inexistente.

Centúria explora a derrocada do princípio de identidade, do qual derivou um dos conceitos mais importantes para a fundamentação da noção de verdade: a correspondência entre pensamento e realidade. Ao contrário de anular a mudança, valorizando, na noção de ser, o que permanece, Manganelli se propõe a explorar o movimento, o incerto, o que não oferece ponto de ancoragem ou de orientação segura. Suspendendo o binarismo da noção de verdade que se opõe à falsidade, à mentira ou ao erro, pode-se dizer que o texto manganelliano amplia o paradigma em relação ao qual algo é considerado verdadeiro. Não é mais possível, sob esse novo paradigma, deduzir um estatuto ontológico do ficcional inferior ao que possui o que se supõe ser o "real", como se a ficção fosse uma espécie de imaginação ou fantasia, ente de razão sem existência in re, como outrora expressava a filosofia escolástica.

Parece que a conclusão a que se pode chegar é que para Manganelli tudo é relativo, incerto, improvável. Desconfia-se do que foi tradicionalmente apresentado como realidade. Não é necessário postular nada que sirva de orientação. Não há nenhum problema em viver no caos. Há uma atitude que se apresenta reiteradamente nos contos de Centúria, que é uma desconfiança em relação a qualquer coisa que tenha a pretensão de verdade, como o personagem do romance-rio Onze, que "desconfia de tudo o que é verdadeiro, e procurou fornecer de si uma imagem que seja difícil dizer-se verdadeira ou falsa" (1995: 34). É envolto nessa "realidade problemática" que o tema do sagrado aparece em Centúria.

Estudos como o de Émile Durkheim (1989), Rudolf Otto (1992) e Mircea Eliade (1992) consideram o sagrado aquilo que, colocando-se fora da história e da cultura e pretendendo-se objetivo, "real" e absoluto, se apresenta como princípio organizador da existência humana. É o que distingue tempos no tempo e espaços no espaço, atribuindo-Thes um caráter diferenciado e elevando-os a um estatuto ontológico superior, em oposição a outros tempos e espaços considerados comuns e corriqueiros. 0 sagrado, pretensamente estável e permanente, é considerado, por quem nele crê, 
capaz de dar legitimidade ao modo de organização da sociedade em que está inserido e de garantir a identidade que permite a tal grupo dizer, de um espaço físico socialmente ordenado, "nosso mundo", distinguindo-o do que se acredita não poder ser assim denominado.

A suposta necessidade de orientação torna inerentes ao conceito de sagrado termos como ser, real, cosmos, mundo, verdade, em oposição à "não-realidade". Postula-se a existência de um "ponto fixo", um "centro", e absolutiza-se a transcendência do "Ser", elevando-o à ordem do eterno, da certeza, da verdade única e unívoca, do que protege do caos.

0 homem manganelliano, entretanto, é adaptado à existência no caos. Não sente necessidade de orientar-se a partir de um ponto fixo e, ainda que o desejasse, não haveria nada que pudesse orientar a ação, pois, para ele, tudo está em permanente movimento. Assim também não há fundamento que permita definir o que é verdadeiro, pois não há elementos suficientes para estabelecer uma realidade paradigmática, com a qual a verdade seria uma conformação. Não existindo uma realidade paradigmática, a pretensão à verdade perde seu significado.

Essa realidade caótica de Manganelli encontra um paralelo num texto de Deleuze e Guattari. Todo pensamento, como afirmam esses autores, é uma luta contra o caos. É uma tentativa de encadear, através das semelhanças, da contigüidade, da causalidade, as "idéias que fogem, que desaparecem apenas esboçadas, já corroídas pelo esquecimento ou precipitadas em outras". Pensar é associar idéias de acordo com "regras protetoras" que instauram "um pouco de ordem" (1992: 259).

A filosofia, a ciência e a arte, que, para Deleuze e Guattari, são as "três grandes formas de pensamento", se definem e se distinguem entre si pelo modo como enfrentam o caos. Este se caracteriza não pela ausência de determinações, mas pela impossibilidade de relação entre elas:

Define-se o caos menos por sua desordem que pela velocidade infinita com a qual se dissipa toda forma que nele se esboça. É um vazio que não é um nada, mas um virtual, contendo todas as partículas possiveis e suscitando todas as formas possiveis que surgem para desaparecer logo em seguida, sem consistência nem referência, sem conseqüência. É uma velocidade infinita de nascimento e de esvanecimento. (1992: 153) 


\section{EM TESE}

Belo Horizonte, v. 6, p. I-253, ago. 2003

Deleuze e Guattari, servindo-se de uma imagem que encontram em Lawrence, afirmam que, permanentemente, os homens buscam as "opiniões prontas" que, como uma espécie de "guarda-sol", os protegem do caos. Diferentemente, a filosofia, a arte e a ciência - "realidades Caóides" - exigem que, ao invés de buscar proteção, instaurem-se planos que não anulem e sim enfrentem o risco de mergulhar nessa virtualidade.

0 sagrado, ao contrário, quer aniquilar o caos para devolver ao homem a certeza das opiniões prontas e acabadas. Pretendendo instaurar essa certeza e constituir-se como ponto de referência e de orientação, ele não pode colocar-se senão como aquilo "que está absolutamente fora do domínio das coisas habituais e compreensiveis" (0tto, 1992: 39), e apresentar-se como algo afastado do humano, o "totalmente outro", pois na "velocidade infinita de nascimento e de esvanecimento" (Deleuze e Guattari, 1992: 153) e na virtualidade do caos não é possível constituir pontos fixos ou definitivos marcos de orientação. As religiões, prosseguem Deleuze e Guattari, pintam sobre o "guarda-sol um firmamento, como as figuras de uma Urdoxa [opinião primordial, originária] de onde derivariam nossas opiniões" (1992: 260). É nesse sentido que o sagrado se define como uma releitura ou explicação da realidade a partir da busca de espaços e tempos qualitativamente diferenciados, sólidos, fortes, significativos o suficiente para garantir limites entre o ser e o nada, a ordem e o caos.

Em Centúria não existem tais limites e nem são pensados como necessários. Não há nada que possa ser descrito como "absolutamente diferente do profano" (Eliade, 1992: 17) ou "totalmente outro" (0tto, 1992). Não se distinguem nem mesmo os âmbitos do sagrado e do profano. Não há ruptura. Há uma completa mistura entre o real e o irreal, o fantástico, o onírico. Os estados que se julgam ser alterações da mente (a embriaguez, a alucinação) não são menos importantes do que a suposta normalidade. 0 caos existe no cosmos; o cosmos é também um caos. A ordem que se suporia oposta à desorientação caótica aparece, em Centúria, apenas como comportamento obsessivo, compulsivo, absurdo.

0 sagrado (entendido como algo que significa uma interrupção da relatividade e da efemeridade) aparece em Centúria como mais uma incerteza. Deus é 
posto como uma possibilidade, mas constantemente escapa ao homem. Exemplo disso é a história do "cavalheiro" que "havia descoberto a prova irrefutável da existência de Deus", mas esquece "a exata formulação de algumas passagens da demonstração" e acaba por concluir que, embora algo resultasse "indiscutivelmente verdadeiro, inatacável", era "impossível de se fixar numa fórmula inesquecível" (Manganelli, 1995: 20-21). Desconfia-se de Deus, pois nada que tenha a pretensão de ser verdadeiro deve ser levado por demais a sério, pois não há o que justifique tal pretensão: Deus - afirma Manganelli em um outro texto - é uma "hipótese inecessária" (Manganelli, 1982: 31).

Poder-se-ia dizer que, em Centúria, se expressa a crise do sagrado. Se o sagrado se define como uma pretensa "Urdoxa" (Deleuze e Guattari, 1992: 260), uma opinião primordial da qual derivariam todas as outras, funcionando, desse modo, como princípio suficiente de legitimação do conhecimento da verdade e de proteção do homem contra o caos, pode-se dizer que os personagens de Manganelli prescindem dessa proteção. 0 papel desempenhado pelo sagrado cede lugar a outros marcos imanentes, provisórios e substituíveis e a legitimação deixa de ser uma necessidade a ser preenchida com o definitivo e o imutável.

Como afirma Lipovetsky a respeito do homem contemporâneo, pode-se dizer dos personagens de Centúria que não há uma busca de sentido existencial: "a própria necessidade de sentido foi varrida de cena e a existência indiferente ao sentido pode desdobrar-se sem patético nem abismo, sem aspiração a novas tábuas de valores" (1989: 37).

A julgar pelos paradigmas fundacionistas, o mundo de Centúria é um delírio; sob a perspectiva manganelliana, porém, são leituras diferentes sobre realidades plurais, libertas da tirania metafísica da perfeita identidade das palavras com o ser e com a verdade. Poder-se-ia pensar em um "efeito de real", cuja representação o homem manganelliano reorganiza sempre de novo. 


\section{EM TESE}

Belo Horizonte, v. 6, p. I-253, ago. 2003

ABSTRACT :

This essay aims at discussing Centúria, by Giorgio Manganelli, focusing on the failure of the metaphysical legitimation of notions such as being, reality, and the sacred.

KEY WORDS: the sacred, metaphysics, fiction, reality.

BARNI, Roberta. A propósito de Manganelli. In: Manganelli, Giorgio. Centúria; cem pequenos romancesrio. São Paulo: Iluminuras, 1995. p. 213-217.

CALVIN0, Italo. Introduzione. In: Manganelli, Giorgio. Centuria; cento piccoli romanzi fiume. 2. ed. Milano: Adelphi, 1998. p. 9-13.

DELEUZE, Gilles, Guattari, Félix. O que é filosofia? Rio de Janeiro: Ed.34, 1992.

DERRIDA, Jacques. Fé e saber; as duas fontes da "religião" nos limites da simples razão. In: Derrida, Jacques, Vattimo, Gianni (Dir.). A religião. Lisboa: Relógio d'Água, 1997. p. 9-93.

DURKHEIM, Émile. As formas elementares de vida religiosa (o sistema totêmico na Austrália). São Paulo: Paulinas, 1989.

ELIADE, Mircea. Imagens e simbolos; ensaio sobre o simbolismo mágico-religioso. São Paulo: Martins Fontes, 1991.

- O sagrado e o profano; a essência das religiões. São Paulo : Martins Fontes, 1992.

HERÁClito. Fragmentos. Apud: Pessanha, José Américo Motta. Os pré-socráticos: vida e obra. In: Souza, José Cavalcante de (Superv.). Os pré-socráticos; fragmentos, doxografia e comentários. São Paulo: Nova Cultural, 1996. p. 3-34. (Os Pensadores)

Il novellino [on line]. [Citado em 20 de dezembro de 2000]. Disponível na Internet: http://dobc.unipv.it/ scrineum/wight/novellino.htm. 
LIPOVETSKY, Gilles. A era do vazio; ensaio sobre o individualismo contemporâneo. Lisboa: Relógio d'Água, 1989 .

LOMBARDI, Andrea. Apresentação. In: Manganelli, Giorgio. Hilarotragoedia. Rio de Janeiro: Imago, 1993. p. 9-18.

MANGANELLI, Giorgio. Centuria; cento piccoli romanzi fiume. 2. ed. Milano: Adelphi, 1998. (Trad. brasileira: São Paulo: Iluminuras, 1995.)

- Hilarotragoedia. 3. ed. Milano: Adelphi, 2001. (Trad. brasileira: Rio de Janeiro: Imago, 1993.)

$\overline{1985}$.

- La letteratura come menzogna. Milano: Adelphi, $\overline{1982}$. - Pinochio: un libro parallelo. Torino: Einaudi, 0TT0, Rudolf. O sagrado. Lisboa: Edições 70, 1992. PAZ, 0ctavio. Convergências: ensaios sobre arte $e$ literatura. Rio de Janeiro: Rocco, 1991. p. 7-44: Leitura e contemplação; p. 97-115: A nova analogia: poesia e tecnologia.

- Os filhos do barro: do romantismo à vanguarda. Rio de Janeiro: Nova Fronteira, 1984.

PESSANHA, José Américo Motta. Os pré-socráticos: vida e obra. In: Souza, José Cavalcante de (Superv.). Os pré-socráticos; fragmentos, doxografia e comentários. São Paulo: Nova Cultural, 1996. p. 3-34. (Os Pensadores) PIMENTA, 01 ímpio. A invenção da verdade. Belo Horizonte: Ed. UFMG, 1999.

VATTIMO, Gianni. 0 rasto do rasto. In: Derrida, Jacques, Vattimo, Gianni (Dir.). A religião. Lisboa: Relógio d'Água, 1997. p. 41-75.

- Creer que se cre. Buenos Aires: Paidós, 1996. 